Supporting Information for

\title{
Pyrolytic Treatment and Fertility Enhancement of Soils Contaminated with Heavy Hydrocarbons
}

\author{
Julia E. Vidonish, Kyriacos Zygourakis, Caroline A. Masiello, Xiaodong Gao,
} Jacques Mathieu, and Pedro J.J. Alvarez*

Rice University, Houston, TX, 77005

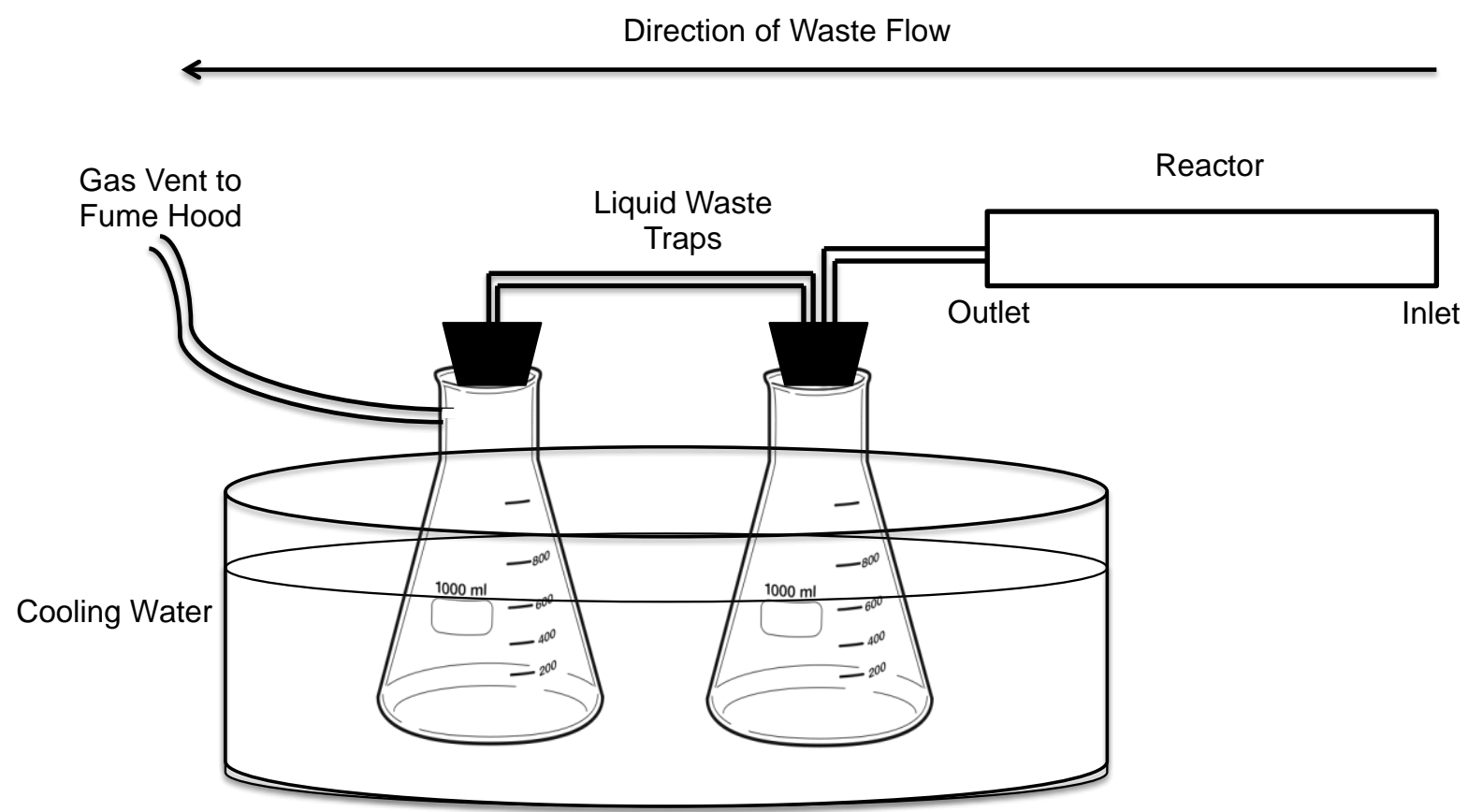

Figure S1: Waste trap for pyrolysis reactor. Oil and moisture flows through the outlet at the end of the pyrolysis reactor and condenses into flasks or is vented to a fume hood. 


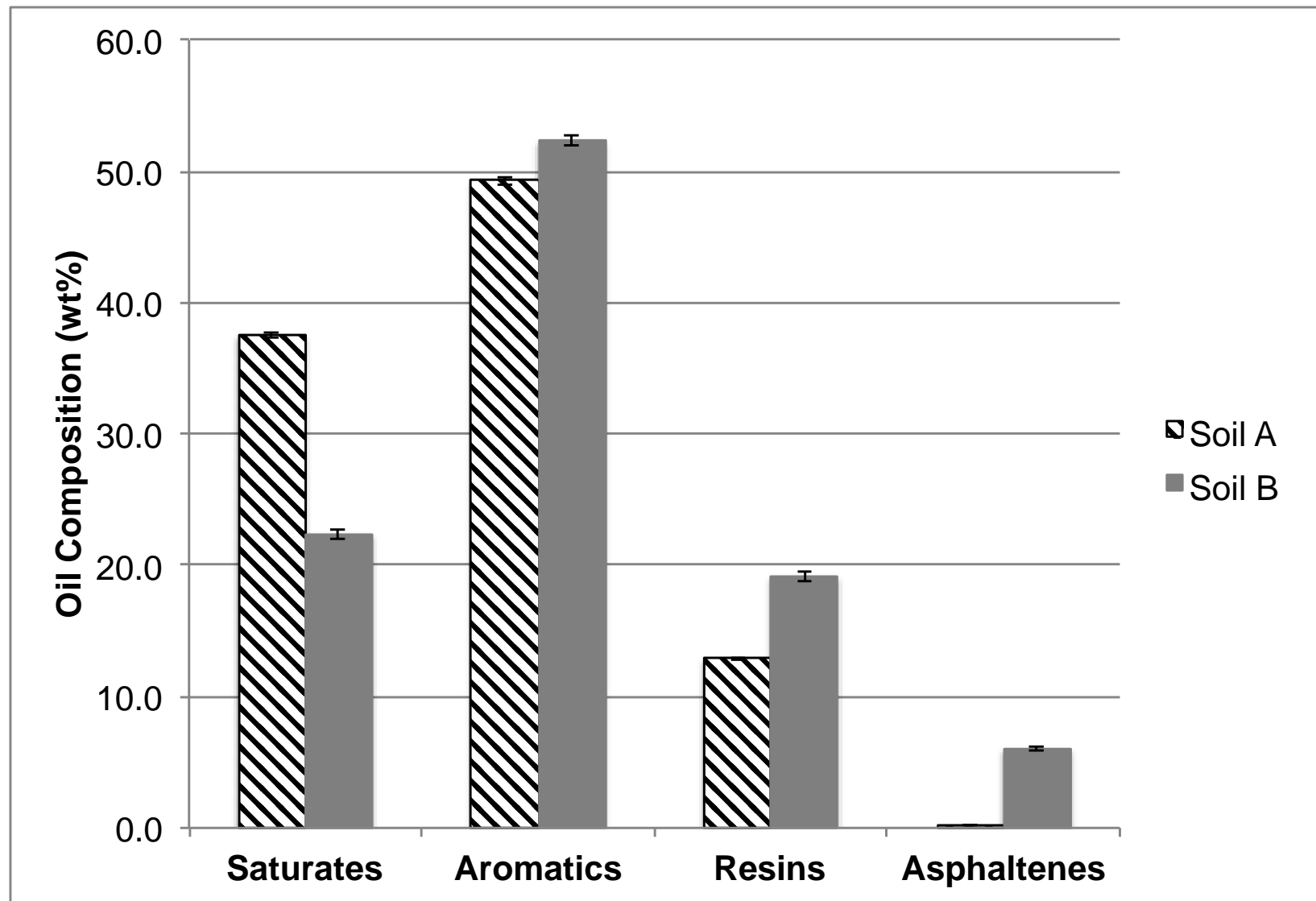

Figure S2. SARA analysis for contaminated soils. As shown in thermogravimetric analysis, soil $B$ contains higher content of heavy hydrocarbons than soil A, which form coke during pyrolysis (SARA analysis conducted by Weatherford Labs, Houston, TX). 


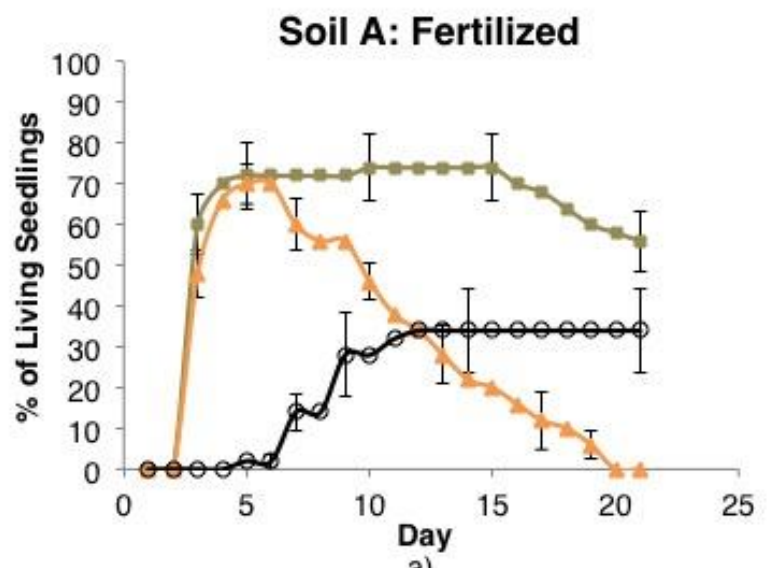

a)

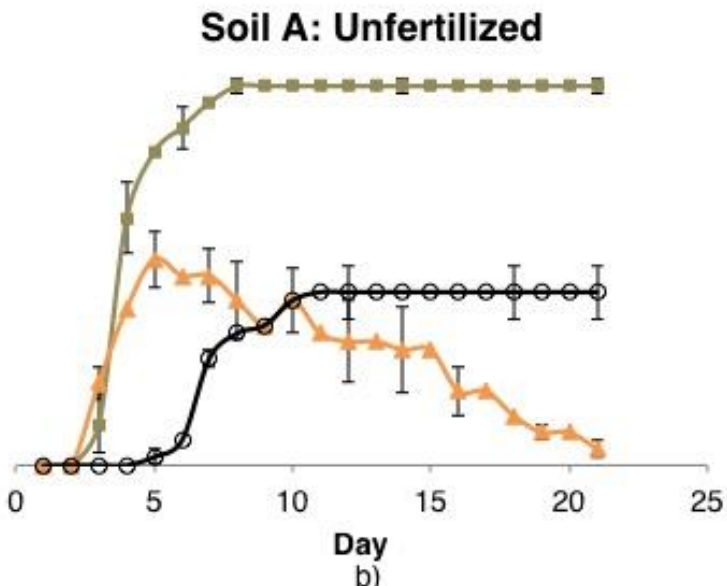

Soil B: Unfertilized

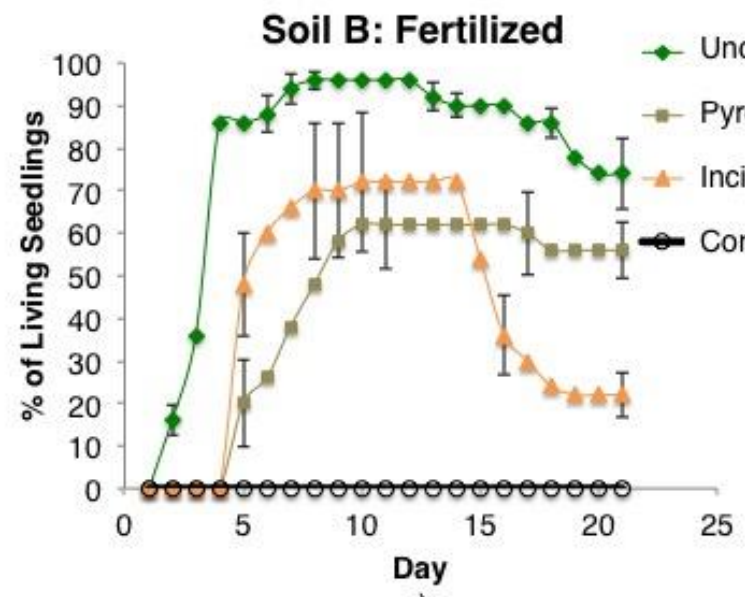

c)

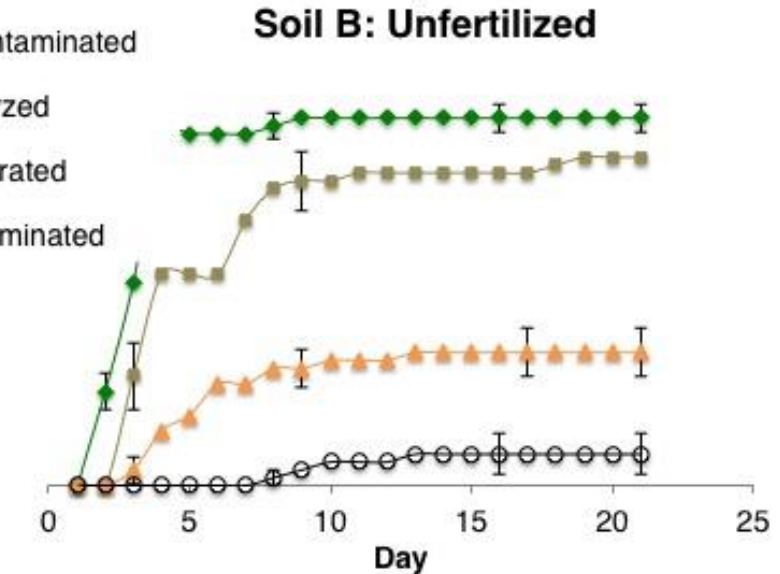

d)

Figure S3. Percentage of living lettuce seedlings for 21 days. Seedlings were counted after germination and removed in case of death. Pyrolyzed soil showed higher germination counts than untreated and incinerated soil. Seedlings in pyrolyzed soil were significantly heavier than in the other treatments. 


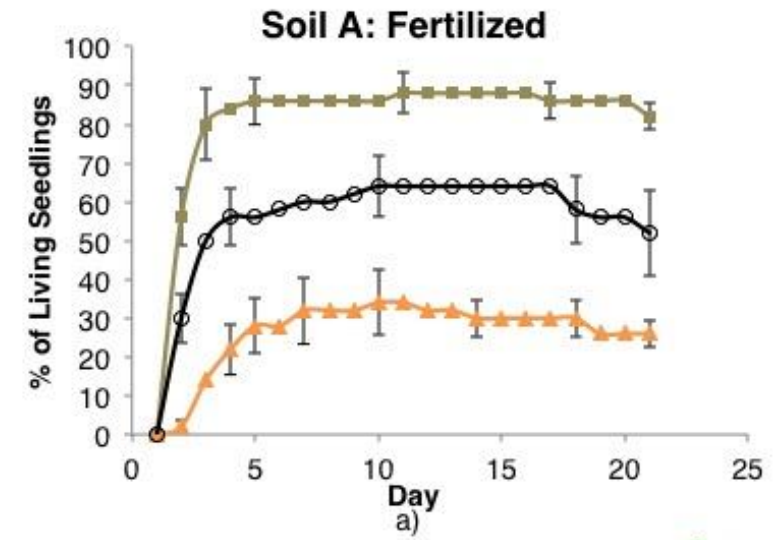

a)

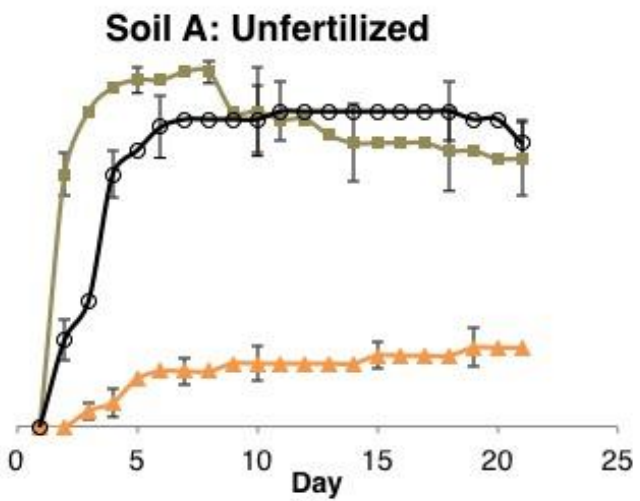

b)

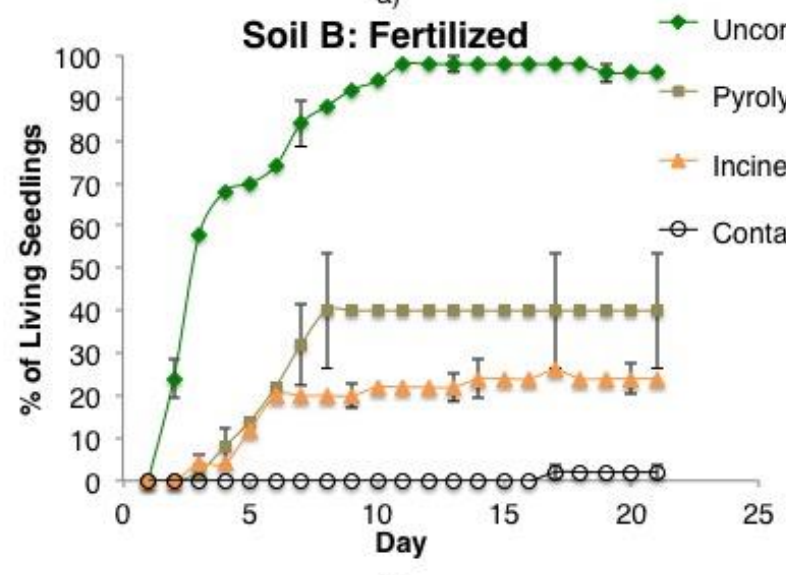

c)
Soil B: Unfertilized

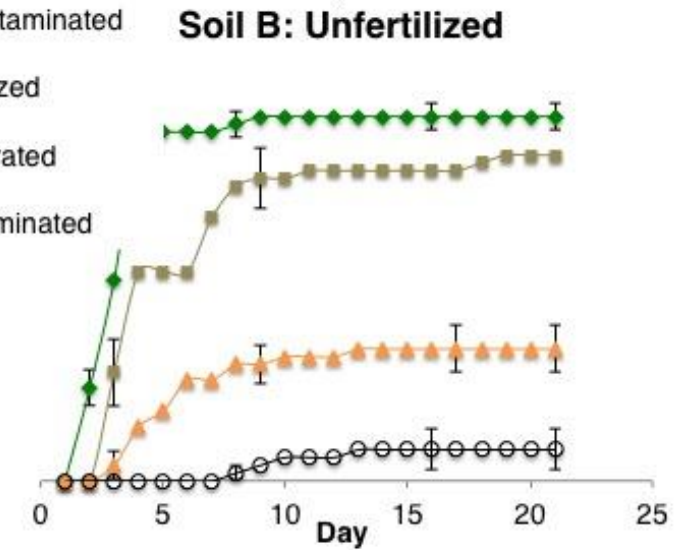

d)

Figure S4. Percentage of living Arabidopsis seedlings for 21 days. Pyrolyzed soil shows higher germination counts than untreated and incinerated soil, and a higher number of seedlings at the end of the experiment. As discussed previously, the seedlings in pyrolyzed soil are significantly heavier than in the other treatments. 
Table S1. Average dry weights of lettuce and Arabidopsis.

\begin{tabular}{|c|c|c|c|c|c|}
\hline \multirow{3}{*}{ Soil } & \multirow{3}{*}{ TPH } & \multicolumn{4}{|c|}{ 21-Day Dry Weight (mg) } \\
\hline & & \multicolumn{2}{|c|}{ Fertilized } & \multicolumn{2}{|c|}{ Unfertilized } \\
\hline & & Lettuce & Arabidopsis & Lettuce & Arabidopsis \\
\hline A, Untreated & $15,000 \mathrm{mg} / \mathrm{kg}$ & 7.5 & 0.15 & 5.41 & 0.14 \\
\hline $\begin{array}{l}\text { A, Pyrolyzed } \\
\left(420^{\circ} \mathrm{C}\right)\end{array}$ & $<4 \mathrm{mg} / \mathrm{kg}$ & 19.88 & 1.67 & 7.35 & 0.50 \\
\hline A, Incinerated & $<4 \mathrm{mg} / \mathrm{kg}$ & 0.02 & 0.00 & 0.02 & 0.00 \\
\hline B, Background & N/A & 4.87 & 0.09 & 1.38 & 0.01 \\
\hline B, Untreated & $19,000 \mathrm{mg} / \mathrm{kg}$ & 0.08 & 0.00 & 0.23 & 0.00 \\
\hline $\begin{array}{l}\text { B, Pyrolyzed } \\
\left(420^{\circ} \mathrm{C}\right)\end{array}$ & $290 \mathrm{mg} / \mathrm{kg}$ & 0.65 & 0.02 & 0.55 & 0.02 \\
\hline B, Incinerated & $<4 \mathrm{mg} / \mathrm{kg}$ & 0.41 & 0.00 & 0.29 & 0.00 \\
\hline
\end{tabular}


Table S2. PAH analysis before and after pyrolytic treatment, and comparison with Texas Tier 1 screening levels.

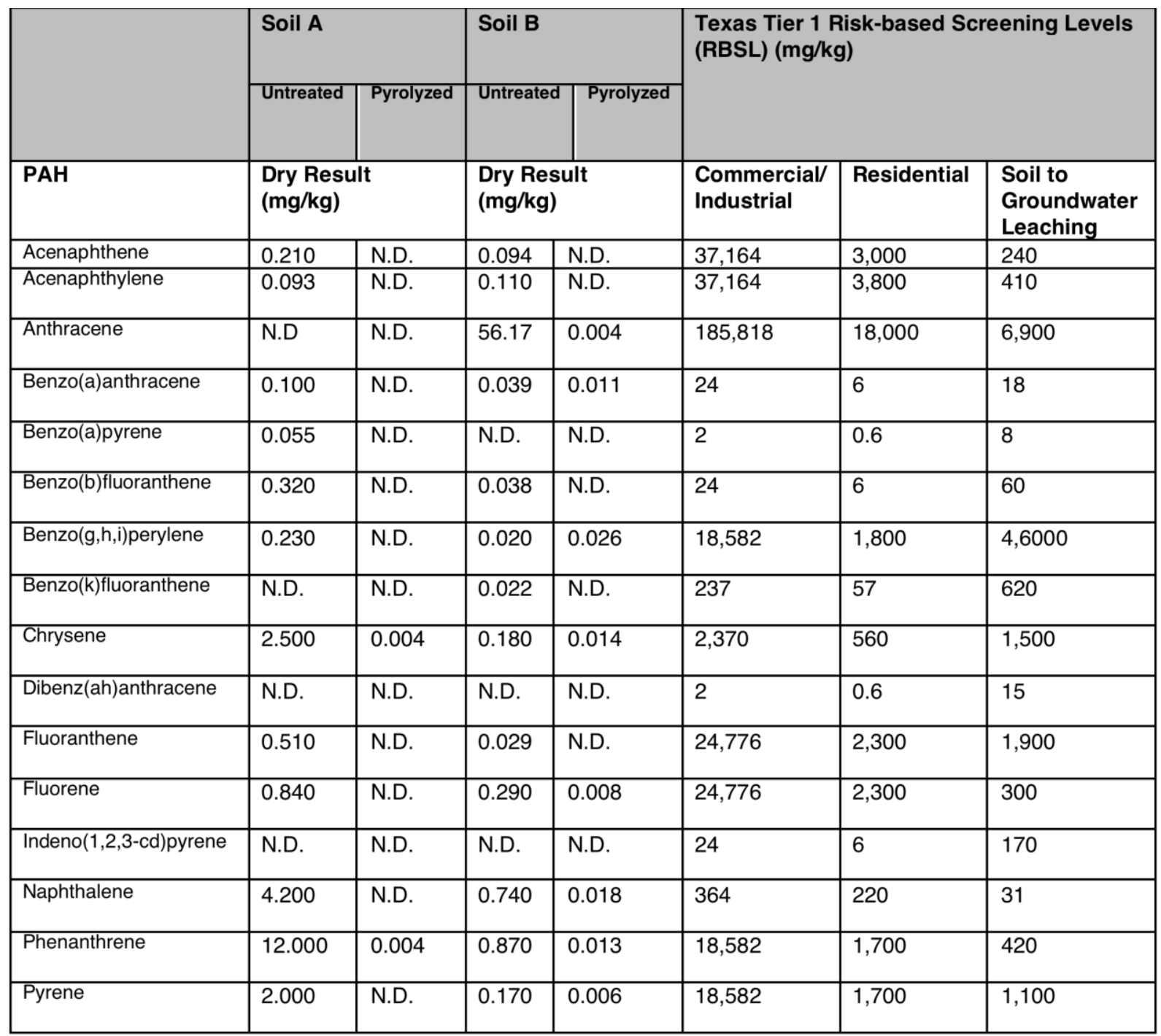

